\title{
Produção e qualidade de uvas de mesa 'Sugraone' sobre diferentes porta-enxertos no Submédio do Vale do São Francisco
}

\author{
Production and quality of table grapes 'Sugraone' on different rootstocks in the São Francisco \\ River Valley
}

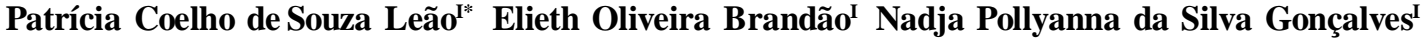

\section{RESUMO}

\begin{abstract}
O presente trabalho teve como objetivos avaliar o comportamento agronômico da cultivar de uva de mesa sem sementes Sugraone sobre quatro porta-enxertos nas condições do Submédio do Vale do São Francisco. O experimento foi conduzido em um vinhedo comercial no município de Sento Sé-BA durante quatro ciclos de produção (2002 à 2004), em sistema de condução do tipo latada e irrigação por gotejamento. Os tratamentos consistiram de quatro cultivares de porta-enxerto ('Paulsen 1103', 'SO4', 'Harmony' e '420A'), utilizando-se delineamento experimental em blocos ao acaso. Foram obtidas maiores produções por planta e vigor vegetativo sobre o porta-enxerto 'Paulsen 1103'. Também observou-se uma tendência de maior massa de cachos, massa e tamanho de bagas sobre este porta-enxerto, embora tenham ocorrido variações entre os ciclos de produção. O porta-enxerto exerceu influência sobre o teor de sólidos solúveis totais, mas não afetou a acidez total e a relação SST/ATT dos frutos.
\end{abstract}

Palavras-chave: videira, uvas sem sementes, Vitis vinifera, produtividade.

\section{ABSTRACT}

The present work aimed to evaluate the agronomic performance of the seedless grape cultivar Sugraone on four rootstocks in the São Francisco Valley. The trial was carried out in a commercial vineyard in Sento Sé, State of Bahia for four seasons (2002 to 2004). The treatments were four cultivars of rootstock ('Paulsen 1103', 'SO4', 'Harmony' and '420A'), using a randomized block design. The highest yield per plant and vegetative vigor were obtained on the rootstock Paulsen 1103. Also there was a tendency for higher mass of bunches, mass and size of berries on the same rootstock, although there were variations between seasons. The rootstock showed positive influence on the content of soluble solids, but did not affect the total acidity and TSS/TA. Young plants of grapevine cv. Sugraone showed good agronomic performance on Paulsen 1103, but it is important to continue the studies for a larger number of years to recommend their use in the São Francisco Valley.

Key words: grapevine, seedless grape, Vitis vinifera, yield.

\section{INTRODUÇÃO}

Características agronômicas e fisiológicas das cultivares copa como vigor, produção, tamanho de cachos e bagas, repartição de fotoassimilados, teor de açúcares e acidez dos frutos e outros compostos importantes para a qualidade dos vinhos podem ser influenciados pelos porta-enxertos. Entretanto, a escolha do porta-enxerto na viticultura depende das condições de solo de cada região produtora e, dentro de uma região, ainda pode sofrer muitas variações, o que faz com que esta seja uma escolha difícil e os trabalhos de pesquisa devem ser repetidos para cada local de cultivo.

No Brasil, os trabalhos de pesquisa estão relacionados, sobretudo, ao estudo sobre o comportamento agronômico das cultivares copa sobre diferentes porta-enxertos, destacando-se a cultivar 'Niagara Rosada' com o maior número de trabalhos realizados. PAULETTO et al. (2001), estudando a cultivar 'Niagara Rosada' sobre os porta-enxertos 'IAC 313', 'IAC 766', 'Ripária do Traviú', 'Kober 5BB' e 'Schwarzmann', observaram que maiores vigor e

'Embrapa Semiárido, BR 428, Km 152, CP 23, Zona Rural, 56300-970, Petrolina, PE, Brasil. E-mail: patricia @cpatsa.embrapa.br. *Autor para correspondência. 
produção foram obtidos sobre 'IAC 313' e 'IAC 766'. ALVARENGA et al. (2002) avaliaram a mesma cultivar sobre os porta-enxertos 'IAC 572', 'IAC 313', 'IAC 766', '420 A', '1103 Paulsen', 'Ripária do Traviú', '196-17 C', 'Gravesac' e '101-14' em condições de solos ácidos. Eles observaram maiores produções sobre os portaenxertos IAC, '1103 Paulsen' e 'Ripária do Traviú', enquanto a enxertia sobre 'Gravesac' e '420 A' antecipou a maturação. MOTA et al. (2009) avaliaram o efeito de nove porta-enxertos sobre a produção e a composição química das bagas das cultivares 'Niágara Rosada' e 'Folha de Figo' e observaram que o portaenxerto IAC 572 proporcionou maiores produções, porém com prejuízo na qualidade dos frutos. $\mathrm{O}$ desempenho agronômico das cvs. 'Crimson Seedless' e 'Superior Seedless' foi avaliado por FELDBERG et al. (2007) em Jaíba, MG, obtendo-se melhores respostas para produção sobre o porta-enxerto Paulsen 1103. Esse porta-enxerto também promoveu o melhor desenvolvimento vegetativo na cultivar 'BRS Violeta', no Paraná (SILVA et al., 2010).

Apesar da crescente importância do cultivo de uvas de mesa sem sementes no Submédio do Vale do São Francisco, estudos de avaliação de portaenxertos são inexistentes nessa região, destacando-se apenas o trabalho de FREIRE et al. (1991), no qual o porta-enxerto Harmony proporcionou maior produtividade e peso de cachos à cultivar Thompson Seedless.

O objetivo do presente trabalho foi avaliar os efeitos de quatro porta-enxertos sobre a produção e características físico-químicas do cacho de videira Sugraone, nas condições do Submédio do Vale do São Francisco.

\section{MATERIAL E MÉTODOS}

O experimento foi instalado em novembro de 2000 em um vinhedo comercial no município de Sento Sé, Estado da Bahia (9॰44'45' S; 41 ${ }^{\circ} 53^{\prime} 06^{\prime \prime}$ O; altitude $410 \mathrm{~m})$, localizado às margens do lago de Sobradinho, na região do Submédio do Vale do São Francisco. O clima da região pode ser classificado, segundo Köepen, como tipo Bswh, que corresponde a uma região semiárida muito quente.

$\mathrm{O}$ experimento foi conduzido durante os anos de 2002 a 2004, em quatro ciclos de produção. As plantas foram conduzidas em latada no espaçamento $3,5 \times 3 \mathrm{~m}$ e irrigadas por gotejamento. Foram realizadas duas podas de produção anuais. Os tratos culturais, nutrição, irrigação e tratamentos fitossanitários foram realizados de acordo com as recomendações para a cultura da videira na região.
A cultivar 'Sugraone' (Vitis vinifera L.) foi enxertada sobre quatro porta-enxertos: 'Harmony', 'SO4', '420-A' e 'Paulsen 1103', utilizando-se um delineamento experimental em blocos ao acaso com três repetições. As parcelas foram compostas por seis plantas.

Foram avaliadas as características relacionadas à produção e qualidade dos frutos: porcentagem de brotação e fertilidade de gemas; produção por planta $(\mathrm{kg})$; massa média de cachos $(\mathrm{g})$; massa $(\mathrm{g})$, comprimento $(\mathrm{mm})$ e diâmetro $(\mathrm{mm})$ médio de bagas; teor de sólidos solúveis totais-SST ( $\left.{ }^{\circ} \mathrm{Brix}\right)$; acidez total titulável-ATT (\% ácido tartárico) e relação SST/ATT. O vigor das plantas foi mensurado pela massa da parte aérea, em quilos, determinada após a poda. A porcentagem de brotação foi calculada pela relação entre número de gemas brotadas por número de gemas total da planta, multiplicada por 100. A porcentagem de fertilidade real de gemas, por sua vez, foi determinada pela relação entre número de gemas frutíferas por número de gemas total, multiplicada por 100. A massa média dos cachos foi obtida pela relação entre massa da produção total da planta e número de cachos por planta. Utilizou-se uma amostra de cinco cachos por planta e 10 bagas por cacho para avaliação das medidas de massa, comprimento e diâmetro de bagas.

\section{RESULTADOS E DISCUSSÃO}

A produção por planta da cultivar de uva sem sementes 'Sugraone' foi mais elevada em todos os ciclos, sobre o porta-enxerto 'Paulsen 1103'.

Já no primeiro ciclo de produção, foram obtidos sobre este porta-enxerto, $16,6 \mathrm{~kg}$ por planta, diferindo significativamente de 'Harmony' e '420A' (Tabela 1). No ciclo seguinte, no primeiro semestre de 2003, a produção da videira foi reduzida em todos os porta-enxertos (Tabela 2), possivelmente consequência de alternância entre safras, que comumente ocorre em vinhedos que realizam duas safras por ano.

Por outro lado, no quarto ciclo, observouse o aumento da produção em todos os porta-enxertos em relação aos ciclos anteriores (Tabela 3 ). Conforme se pode observar na tabela 4 , a média de produção para os quatro ciclos avaliados demonstrou que o portaenxerto 'Paulsen 1103', embora tenha diferido significativamente apenas do porta-enxerto ' $420 \mathrm{~A}$ ', resultou em um aumento de $24,5 \%$ na produção da cultivar 'Sugraone', quando comparada ao portaenxerto SO4, e de 40,5\% comparada ao 'Harmony', o que correspondeu a produtividades médias estimadas em $12 \mathrm{t} \mathrm{ha}^{-1}, 9 \mathrm{tha}^{-1} \mathrm{e} 7 \mathrm{tha}^{-1}$, respectivamente, sobre os 
Tabela 1 - Média e coeficiente de variação (CV) para características agronômicas da videira 'Sugraone' sobre quatro porta-enxertos. Sento Sé, BA, segundo semestre de 2002 .

\begin{tabular}{lllllllllll}
\hline Porta-enxerto & $\mathrm{PR}^{1}$ & $\mathrm{MP}$ & $\mathrm{NC}$ & $\mathrm{MC}$ & $\mathrm{MB}$ & $\mathrm{CB}$ & $\mathrm{DB}$ & $\mathrm{SST}$ & ATT & SST/ATT \\
\hline 1103P & $16,60 \mathrm{a}$ & $4,5 \mathrm{a}$ & $38 \mathrm{a}$ & $507 \mathrm{a}$ & 6,19 & 24,61 & $20,71 \mathrm{a}$ & $16,63 \mathrm{a}$ & 0,50 & 33,51 \\
Harmony & $7,42 \mathrm{~b}$ & $2,77 \mathrm{c}$ & $26 \mathrm{ab}$ & $307 \mathrm{ab}$ & 6,19 & 24,80 & $20,60 \mathrm{a}$ & $15,43 \mathrm{ab}$ & 0,46 & 33,84 \\
420A & $5,99 \mathrm{~b}$ & $3,07 \mathrm{bc}$ & $18 \mathrm{~b}$ & $287 \mathrm{~b}$ & 5,47 & 23,52 & $19,69 \mathrm{~b}$ & $15,30 \mathrm{~b}$ & 0,45 & 33,88 \\
SO4 & $9,26 \mathrm{ab}$ & $3,72 \mathrm{ab}$ & $25 \mathrm{ab}$ & $383 \mathrm{ab}$ & 6,19 & 24,58 & $20,61 \mathrm{a}$ & $15,47 \mathrm{ab}$ & 0,50 & 31,16 \\
Média & 9,82 & 3,51 & 27 & 371 & 6,01 & 24,38 & 20,40 & 15,70 & 0,48 & 33,09 \\
CV $(\%)$ & 43,45 & 12,64 & 25,89 & 21,4 & 5,87 & 2,69 & 1,81 & 3,99 & 5,91 & 4,38 \\
\hline
\end{tabular}

${ }^{1}$ PR: produção por planta $(\mathrm{kg})$; MP: massa da parte aérea $(\mathrm{kg})$; NC: número de cachos por planta; MC: massa média do cacho (g); MB: massa média da baga (g); CB: comprimento médio da baga ( $\mathrm{mm})$; DB: diâmetro médio da baga (mm); SST: sólidos solúveis totais ( ${ }^{\circ}$ Brix); ATT: acidez total titulável (\% ácido tartárico).

${ }^{2}$ Médias seguidas pela mesma letra na coluna não diferem entre si pelo teste de Duncan ao nível de 5\% de probabilidade.

porta-enxertos 'Paulsen 1103', 'SO4' e 'Harmony'. O porta-enxerto 'Paulsen 1103' também aumentou a produção das cultivares 'Sugraone' e 'Crimson Seedless', comparado ao 'IAC 572', em Jaíba, MG (FELDBERG et al., 2007) e na cultivar Itália (EZZAHOUANI \& LARRY, 1997).

As plantas enxertadas sobre 'Paulsen 1103' e 'SO4' apresentaram maior vigor vegetativo do que aquelas enxertadas sobre 'Harmony' e '420A', que demonstraram ser porta-enxertos que conferem menor vigor à copa. Entretanto, diferenças estatísticas significativas foram observadas apenas no primeiro ciclo de produção, destacando-se o vigor das plantas sobre 'Paulsen 1103', comparado ao 'Harmony' e '420A' (Tabela 1).

O maior vigor da cultivar 'Sugraone' sobre 'Paulsen 1103' e 'SO4' pode explicar as maiores produções obtidas sobre estes porta-enxertos nos quatro primeiros ciclos de produção, avaliados neste trabalho. Esse resultado está de acordo com aqueles obtidos por ALVARENGA et al. (2002) em plantas jovens de 'Niágara Rosada', no qual as maiores produções foram obtidas nos porta-enxertos mais vigorosos ('IAC 766', 'IAC 572', 'IAC 313', 'P1103' e 'Traviu'), mencionando os autores que, em solos pobres, porta-enxertos mais vigorosos podem proporcionar maiores produções à copa, sem provocar excesso de vegetação, em detrimento da produção.

Correlação positiva entre produção e vigor pode ainda estar relacionada com a idade da planta, pois, em plantas adultas de 'Niágara Rosada', MOTA et al. (2009) observaram correlação negativa entre essas características. O porta enxerto 'Paulsen 1103' também se destacou entre os que imprimiram maior vigor às cultivares de uvas de vinho 'Castelão', 'Trincadeira' e 'Camarate' (CLIMACO et al., 2003), salientando os autores que existe uma relação entre a produção da planta como resultado da afinidade entre copas mais vigorosas e porta-enxertos menos vigorosos e viceversa.

O número e a massa do cacho apresentaram diferenças significativas entre os porta-enxertos 'Paulsen 1103' e '420 A' apenas no primeiro ciclo de produção (Tabela 1). Não foram obtidos os dados para

Tabela 2 - Médias e coeficiente de variação (CV) para características agronômicas da videira 'Sugraone' sobre quatro porta-enxertos. Sento Sé, BA, primeiro semestre de 2003.

\begin{tabular}{lllllllllll}
\hline Porta-enxerto & PR $^{1}$ & MP & NC & MC & MB & CB & DB & SST & ATT & SST/ATT \\
\hline 1103P & 5,12 & 7,94 & 24 & 224 & $5,64 \mathrm{ab}$ & $23,60 \mathrm{ab}$ & 20,10 & $14,00 \mathrm{ab}$ & 0,42 & 33 \\
Harmony & 2,51 & 5,80 & 13 & 195 & $5,93 \mathrm{a}$ & $24,30 \mathrm{a}$ & 20,18 & $14,57 \mathrm{a}$ & 0,43 & 34 \\
420A & 3,92 & 5,58 & 13 & 266 & $4,96 \mathrm{~b}$ & $22,85 \mathrm{~b}$ & 19,07 & $13,67 \mathrm{~b}$ & 0,37 & 37 \\
SO4 & 6,58 & 9,10 & 27 & 221 & $5,90 \mathrm{a}$ & $24,33 \mathrm{a}$ & 20,23 & $14,07 \mathrm{ab}$ & 0,44 & 32 \\
Média & 4,53 & 7,10 & 20 & 226 & 5,60 & 23,77 & 19,89 & 14,08 & 0,42 & 34,19 \\
CV $(\%)$ & 59,17 & 32,14 & 38,18 & 53,15 & 7,40 & 1,97 & 2,83 & 2,09 & 10,25 & 11,65 \\
\hline
\end{tabular}

${ }^{1} \mathrm{PR}$ : produção por planta $(\mathrm{kg})$; MP: massa da parte aérea $(\mathrm{kg})$; $\mathrm{NC}$ : número de cachos por planta; $\mathrm{MC}$ : massa média do cacho (g); MB: massa média da baga (g); CB: comprimento médio da baga (mm); DB: diâmetro médio da baga (mm); SST: sólidos solúveis totais ( ${ }^{\circ}$ Brix); ATT: acidez total titulável (\% ácido tartárico).

${ }^{2}$ Médias seguidas pela mesma letra na coluna não diferem entre si pelo teste de Duncan em nível de 5\% de probabilidade. 
Tabela 3 - Médias e coeficiente de variação (CV) para características agronômicas da videira 'Sugraone' sobre quatro porta-enxertos. Sento Sé, BA, segundo semestre de 2004.

\begin{tabular}{|c|c|c|c|c|c|c|c|c|c|c|c|c|}
\hline Porta-enxerto & $\mathrm{PR}^{1}$ & MP & $\mathrm{NC}$ & $\mathrm{MC}$ & MB & $\mathrm{CB}$ & DB & SST & ATT & SST/ATT & $\begin{array}{l}\text { Fert. } \\
\text { Varas }\end{array}$ & $\begin{array}{l}\text { Fert. } \\
\text { Netos }\end{array}$ \\
\hline $1103 \mathrm{P}$ & 17,13 & 7,42 & 53 & 373 & 6,32 & 24,87 & 21,30 & 16,53 & 0,38 & 43,97 & 24,43 & 36,58 \\
\hline Harmony & 14,64 & 4,12 & 43 & 387 & 6,22 & 24,47 & 20,63 & 16,17 & 0,37 & 43,60 & 24,22 & 53,37 \\
\hline $420 \mathrm{~A}$ & 10,99 & 5,49 & 40 & 308 & 6,06 & 24,33 & 19,97 & 16,93 & 0,37 & 46,24 & 25,24 & 38,28 \\
\hline $\mathrm{SO} 4$ & 15,93 & 6,06 & 44 & 387 & 6,50 & 24,97 & 20,87 & 16,63 & 0,38 & 44,09 & 20,03 & 25,26 \\
\hline Média & 14,67 & 5,77 & 45 & 364 & 6,28 & 24,66 & 20,69 & 16,57 & 0,37 & 44,48 & 23,48 & 38,27 \\
\hline $\mathrm{CV}(\%)$ & 37,08 & 27,47 & 24,60 & 50,03 & 5,19 & 2,98 & 5,89 & 2,32 & 2,49 & 4,69 & 23,27 & 41,55 \\
\hline
\end{tabular}

${ }^{1}$ PR: produção por planta $(\mathrm{kg})$; MP: massa da parte aérea $(\mathrm{kg})$; NC: número de cachos por planta; MC: massa média do cacho (g); MB: massa média da baga (g); CB: comprimento médio da baga $(\mathrm{mm})$; DB: diâmetro médio da baga $(\mathrm{mm})$; SST: sólidos solúveis totais $\left({ }^{\circ} \mathrm{Brix}\right)$; ATT: acidez total titulável (\% ácido tartárico); Fert.: fertilidade real de gemas $(\%)$

${ }^{2}$ Médias seguidas pela mesma letra na coluna não diferem entre si pelo teste de Duncan em nível de 5\% de probabilidade.

número e massa dos cachos no segundo semestre de 2003. Na média de todos os ciclos, o número de cachos das plantas sobre 'Paulsen 1103' foi superior aos demais porta-enxertos, mas diferiu significativamente apenas do '420A', enquanto, em relação à massa do cacho, destacaram-se os porta-enxertos 'Paulsen 1103' e 'SO4', embora não tenham sido observadas diferenças significativas (Tabela 4).

As características relacionadas ao tamanho da baga (massa, comprimento e diâmetro) apresentaram variações entre os porta-enxertos nos diferentes ciclos de produção. O número e massa do cacho apresentou diferenças significativas entre os porta-enxertos 'Paulsen 1103' e '420 A' apenas no primeiro ciclo de produção (Tabela 1). Não foram obtidos os dados para número e massa dos cachos no segundo semestre de 2003 (Tabela 5). Entretanto, o porta-enxerto ' 420 A' promoveu o menor crescimento na massa e tamanho das bagas em todos os ciclos.

O diâmetro das bagas no primeiro ciclo de produção foi inferior no porta-enxerto ' $420 \mathrm{~A}$ ', diferindo significativamente dos demais porta-enxertos (Tabela 1), enquanto, no segundo ciclo de produção, a massa e o comprimento das bagas neste porta-enxerto foi menor, com diferenças significativas em relação ao 'Harmony' e 'SO4' (Tabela 2). A média de todos os ciclos evidenciou pouca influência dos porta-enxertos sobre estas características, não sendo observadas diferenças estatísticas significativas.

$\mathrm{O}$ porta-enxerto $\mathrm{SO} 4$ apresentou um aumento de apenas $8,5 \%$ e $3,2 \%$, respectivamente, para massa e comprimento das bagas em relação ao '420A', enquanto o diâmetro das bagas das plantas enxertadas sobre 'Paulsen 1103' foi 4,74\% superior àquelas enxertadas sobre '420A'. PAULETTO et al. (2001) também observaram pouca influência do porta-enxerto sobre a massa da baga da cultivar 'Niagara Rosada', obtendo efeitos não significativos para essa característica em seis, das sete safras avaliadas.

O valor médio para teor de sólidos solúveis totais (SST) da cultivar 'Sugraone' foi superior a $15^{\circ}$ Brix em todos os ciclos, com exceção do segundo ciclo de produção, o que pode ser considerado satisfatório para essa cultivar (LIMA, 2009).

Tabela 4 - Médias e coeficiente de variação de quatro ciclos de produção para características agronômicas da videira 'Sugraone' sobre quatro porta-enxertos. Sento Sé, BA.

\begin{tabular}{lllllllllll}
\hline Porta-enxerto & PR $^{1}$ & MP & NC & MC & MB & CB & DB & SST & ATT & SST/ATT \\
\hline 1103P & $12,52 \mathrm{a}$ & 6,77 & $38 \mathrm{a}$ & 368 & 6,07 & 24,55 & 20,66 & $15,63 \mathrm{a}$ & 0,48 & 34,03 \\
Harmony & $7,45 \mathrm{ab}$ & 4,83 & $27 \mathrm{ab}$ & 296 & 6,09 & 24,53 & 20,35 & $15,37 \mathrm{~b}$ & 0,46 & 34,45 \\
420A & $6,08 \mathrm{~b}$ & 4,73 & $24 \mathrm{~b}$ & 287 & 5,62 & 23,81 & 19,68 & $15,31 \mathrm{~b}$ & 0,45 & 35,90 \\
SO4 & $9,45 \mathrm{ab}$ & 6,48 & $32 \mathrm{ab}$ & 330 & 6,14 & 24,60 & 20,43 & $15,37 \mathrm{~b}$ & 0,48 & 33,26 \\
Média & 8,87 & 5,70 & 30 & 320 & 5,98 & 24,37 & 20,28 & 15,42 & 0,47 & 34,41 \\
CV $(\%)$ & 21,69 & 19,69 & 19,79 & 25,60 & 4,21 & 1,61 & 2,65 & 0,70 & 3,97 & 4,38 \\
\hline
\end{tabular}

${ }^{1} \mathrm{PR}$ : produção por planta $(\mathrm{kg})$; MP: massa da parte aérea $(\mathrm{kg})$; $\mathrm{NC}$ : número de cachos por planta; MC: massa média do cacho (g); MB: massa média da baga (g); CB: comprimento médio da baga (mm); DB: diâmetro médio da baga (mm); SST: sólidos solúveis totais ( ${ }^{\circ}$ Brix); ATT: acidez total titulável (\% ácido tartárico).

${ }^{2}$ Médias seguidas pela mesma letra na coluna não diferem entre si pelo teste de Duncan em nível de 5\% de probabilidade 
Tabela 5 - Médias e coeficiente de variação (CV) para características agronômicas da videira 'Sugraone' sobre quatro porta-enxertos. Sento Sé, BA, segundo semestre de 2003.

\begin{tabular}{lllllllll}
\hline Porta-enxerto & $\mathrm{PR}^{1}$ & $\mathrm{MP}$ & $\mathrm{MB}$ & $\mathrm{CB}$ & $\mathrm{DB}$ & $\mathrm{SST}$ & ATT & SST/ATT \\
\hline 1103P & $11,23 \mathrm{a}$ & 7,20 & 6,14 & 25,13 & 20,50 & 15,37 & 0,61 & 25,62 \\
Harmony & $5,20 \mathrm{ab}$ & 6,63 & 6,01 & 24,53 & 20,00 & 15,32 & 0,59 & 26,16 \\
420A & $3,40 \mathrm{~b}$ & 4,80 & 5,99 & 24,53 & 20,00 & 15,31 & 0,59 & 26,31 \\
SO4 & $6,03 \mathrm{ab}$ & 7,03 & 5,99 & 24,50 & 20,00 & 15,31 & 0,59 & 25,35 \\
Média & 6,47 & 6,42 & 6,03 & 24,68 & 20,13 & 15,33 & 0,60 & 25,86 \\
CV $(\%)$ & 54,53 & 29,60 & 4,69 & 1,94 & 2017 & 1,03 & 4,92 & 5,30 \\
\hline
\end{tabular}

${ }^{1}$ PR: produção por planta $(\mathrm{kg})$; MP: massa da parte aérea $(\mathrm{kg})$; NC: número de cachos por planta; MC: massa média do cacho (g); MB: massa média da baga $(\mathrm{g})$; CB: comprimento médio da baga $(\mathrm{mm})$; DB: diâmetro médio da baga $(\mathrm{mm})$; SST: sólidos solúveis totais ( ${ }^{\circ}$ Brix); ATT: acidez total titulável (\% ácido tartárico).

${ }^{2}$ Médias seguidas pela mesma letra na coluna não diferem entre si pelo teste de Duncan em nível de 5\% de probabilidade.

O porta-enxerto exerceu uma maior influência sobre o teor de sólidos solúveis totais (SST) no primeiro e segundo ciclos de produção, observandose diferenças significativas entre 'Paulsen 1103' e '420A', no primeiro ciclo, e entre 'Harmony' e '420A' no segundo ciclo. Na média de todos os ciclos (Tabela 4), o teor de sólidos solúveis das bagas no porta-enxerto 'Paulsen 1103' foi superior aos demais porta-enxertos, com diferenças significativas entre eles.

Esse porta-enxerto também promoveu maior teor de sólidos solúveis na cv. 'Xarel.lo' ( $\boldsymbol{V}$. vinifera) na Espanha (PAREJO et al., 1995). PAULETTO et al. (2001) mencionaram que os porta-enxertos tiveram pouca influência no SST da cultivar 'Niagara Rosada' ao longo das safras, mas, na média geral, destacaramse os porta-enxertos 'Kober 5BB' e 'Schwarzmann'. MOTA et al. (2009), estudando nove porta-enxertos e o pé-franco na cultivar Niagara Rosada observaram diferenças no teor de SST apenas entre 'RR 101-14' e os porta-enxertos 'IAC 572', 'IAC 313' e 'IAC 766'. CLIMACO et al. (2003) não observaram influência dos porta-enxertos sobre o acúmulo de sólidos solúveis em três cultivares portuguesas de uvas de vinho.

O valor médio para acidez total titulável (ATT) dos frutos variou de $0,37 \%$, no quarto ciclo, a $0,60 \%$, no terceiro ciclo de produção, demonstrando um teor moderado de acidez total nos frutos dessa cultivar, independente do porta-enxerto utilizado. $\mathrm{O}$ porta-enxerto não afetou a acidez total e nem a relação SST/ATT. Na média geral de todos os ciclos (Tabela 4), foram obtidos os valores mais baixos e mais altos, respectivamente, para ATT e relação SST/ATT, nos frutos das plantas enxertadas sobre o porta-enxerto '420A', embora com pequenas diferenças, comparadas aos outros porta-enxertos.

A fertilidade real de gemas nas varas e nos ramos terciários ou 'netos' foi avaliada apenas no quarto ciclo de produção. Na tabela 3, observa-se que os porta-enxertos não afetaram essa característica. A média para fertilidade real de gemas nas varas da cultivar 'Sugraone' foi $23,48 \%$, esse valor foi superior àquele mencionado por RIBEIRO et al. (2008), que obteve uma fertilidade real média de 17,6\% na cultivar 'Sugraone', e por LEÃO et al. (2003), que observaram, na média de cinco diferentes épocas de poda, uma fertilidade de $12 \%$ nas varas dessa cultivar, no Submédio do Vale do São Francisco. Por sua vez, obteve-se, neste trabalho, uma fertilidade real nos 'netos' de $38,27 \%$, confirmando a importância do manejo da poda em que se realiza um ciclo para formação dos ramos e 'netos' e apenas uma poda de produção por ano.

Os resultados obtidos evidenciaram a influência do porta-enxerto sobre a produção e o vigor de plantas jovens da cultivar 'Sugraone', afetando com menor intensidade o tamanho das bagas e conteúdo de sólidos solúveis e acidez total dos frutos.

\section{CONCLUSÃO}

Maiores produções, vigor vegetativo e teor de sólidos solúveis totais foram obtidos na cultivar 'Sugraone' enxertada sobre 'Paulsen 1103' em relação aos porta-enxertos 'SO4', 'Harmony'e '420A'.

Plantas da cultivar 'Sugraone' enxertadas sobre 420A apresentaram menor produção, vigor vegetativo, massa de cachos, massa de bagas, tamanho de bagas e teor de sólidos solúveis, comparadas aos demais porta-enxertos, não se recomendando a sua utilização nesta cultivar no Submédio do Vale do São Francisco.

Não houve influência dos porta-enxertos sobre acidez total das bagas e relação a sólidos solúveis totais e acidez total titulável. 


\section{REFERÊNCIAS}

ALVARENGA, A.A. et al.. Influência do porta-enxerto sobre o crescimento e produção da cultivar de videira 'niágara rosada' (Vitis labrusca 1. x Vitis vinifera 1.), em condições de solo ácido. Ciência e agrotecnologia, Lavras, Edição Especial, p.14591464, 2002. Disponível em: <http://www.editora.ufla.br/site/ _adm/upload/revista/26-E-2002_12.pdf>. Acesso em: 23 out. 2008 .

CLIMACO, P. et al.. Efeito da casta e do porta-enxerto no vigor e na produtividade da videira. Ciência e Técnica Vitivinícola, Portugal, v.18, n.1, p.1-14, 2003. Disponível em: <http:// www.scielo.oces.mctes.pt/pdf/ctv/v18n1/v18n1a01.pdf>. Acesso em: 23 out. 2008 .

EZZAHOUANI, A.; LARRY, L.E. Effect of rootstock on grapevine water status productivity and grape quality of cultivar 'Italia'. Bulletin de l'OIV, França, v.70, p.703-713,1997.

FELDBERG, N.P. et al. Desempenho agronômico das videiras 'Crimson Seedless' e 'Superior Seedless' no norte de Minas Gerais. Pesquisa Agropecuária Brasileira, Brasília, v.42, n.6, p.777783, 2007. Disponível em: <http://www.scielo.br/pdf/pab/v42n6/ v42n6a03.pdf $>$. Acesso em: 09 mar. 2010. doi: 10.1590/ S0100-204X2007000600003.

FREIRE, L.C.L. et al. Comportamento de uva 'Thompson Seedless' sobre diferentes porta-enxertos na região do Submédio São Francisco. Revista Brasileira de Fruticultura, Cruz das Almas, v.13, n.2, p.129-133, 1991.

LEÃO, P.C.S de; SILVA, E.E.G. da. Brotação e fertilidade de gemas em uvas sem sementes no Vale do São Francisco. Revista Brasileira de Fruticultura, Jaboticabal, v.25, n.3, p.375378, 2003. Disponível em: <http://www.scielo.br/pdf/rbf/v25n3/ 18646.pdf>. Acesso em: 23 out. 2008. doi: 10.1590/S010029452003000300003.

LIMA, M.A.C. Fisiologia, tecnologia e manejo pós-colheita. In: SOARES, J.M.; LEÃO, P.C. de S. (Eds.). A vitivinicultura no Semiárido Brasileiro. Brasília: Embrapa Informação Tecnológica, DF/Embrapa Semiárido: Petrolina, PE, 2009. 756p.

MOTA, R.V. da et al. Produtividade e composição físico-química de bagas de cultivares de uva em distintos porta-enxertos. Pesquisa Agropecuária Brasileira, Brasília, v.44, n.6, p.576582, 2009. Disponível em: <http://www.scielo.br/pdf/pab/ v44n6/a05v44n6.pdf>. Acesso em: 09 mar. 2010. doi: 10.1590/ S0100-204X2009000600005.

PAREJO, J. et al. Sixteen years of monitoring the cultivar 'Xarello' (Vitis vinifera L.) on several rootstocks. Acta Horticulturae, Espanha, v.388, p.123-128, 1995. Disponível em: <http:// www.actahort.org/members/showpdf?session=31620>. Acesso em: 23 out. 2008.

PAULETTO, D. et al. Produção e vigor da videira Niágara Rosada relacionados com o porta-enxerto. Pesquisa Agropecuária Brasileira, Brasília, v.36, n.1, p.115-121, 2001. Disponível em: <http://www.scielo.br/pdf/pab/v36n1/ 4232.pdf>. Acesso em: 23 out. 2008. doi: 10.1590/S0100204X2001000100014

RIBEIRO, V.G. et al. Expressão da fertilidade de gemas da 'Superior Seedless' no município de Petrolina. Revista Caatinga, Mossoró, v.21, n.3, p.231-235, 2008.

SILVA, T.P. da et al. Avaliação de porta-enxertos de videira em condições subtropicais. Bragantia, Campinas, v.69, n.1, p.9397, 2010. Disponível em: <http://www.scielo.br/ scielo.php ? s cript $=\mathrm{sci}_{-}$art text \& pid=S $0006-$ $87052010000100013 \& \operatorname{lng}=p t \& n r m=i s o \& t \operatorname{lng}=p t>$. Acesso em: 21 mar. 2011. doi: 10.1590/S0006-87052010000100013. 